\title{
Check-In Procedures for Plant Cell Entry by Biotrophic Microbes
}

\author{
Andrea Genre and Paola Bonfante \\ Dipartimento di Biologia Vegetale, Università di Torino and IPP-CNR. Viale Mattioli 25, 10125 Torino, Italy
}

Submitted 9 March 2007. Accepted 13 April 2007.

\begin{abstract}
Significant advances in the cell biology of plant-microbe interactions have been achieved recently, to a large extent based on new technical approaches such as the use of fluorescent protein tags in model plants exploited in conjunction with available genetic resources. They have highlighted the pivotal role played by epidermal cells as the first site at which direct cell-to-cell contact takes place between the plant and microbes it may host. Here, we compare the cellular aspects of early biotrophic interactions with symbiotic and pathogenic microbes and evaluate the hypothesis that their hosting by plant cells share common traits related to the necessity of preserving host-cell integrity. The cellular events that accompany cell entry by the different biotrophs are divided into three categories, depending on whether the cellular changes are triggered by diffusible molecules, direct contact, or cell lumen penetration. Similarities and differences mirror the nutritional and developmental strategies of each plant-interacting organism, underlining the fact that plant cell entry represents a key aspect in the establishment of biotrophy.
\end{abstract}

Additional keywords: biotrophic pathogens, cell responses, effector molecules, rhizobia.

In recent years, there has been increasing interest in the cell biology of plant-microbe interactions. New approaches and technical advances have provided plant cell biologists with the latest tools to investigate cell responses in vivo, allowing fascinating trips into intimate plant cell mechanisms (Dhanoa et al. 2006). One of the most important innovations in this sense is the use of the green fluorescent protein (GFP) and its derivatives as live cell markers (Brandizzi et al. 2002). A global view of the application of these recent advances to plant biotrophic interactions highlights the pivotal role played by epidermal cells, the outermost cell layer of plant tissues. These advances complement breakthroughs in genetic and molecular studies of plant-microbe interactions, which are largely documented in several recent reviews (Glazebrook 2005; Oldroyd and Downie 2006; Parniske 2004).

In this review, our goal is to evaluate the hypothesis that the plant responses leading to intracellular accommodation of biotrophic microbes share common traits, irrespectively of the symbiotic or pathogenic status of the partner. We focus on the

Corresponding author: Andrea Genre: E-mail: andrea.genre@unito.it

* The $e$-Xtra logo stands for "electronic extra" and indicates that Figure 1 appears in color online. cellular aspects of early interactions with biotrophs such as rhizobia, arbuscular mycorrhizal (AM), and pathogenic fungi.

The main scientific interest in plant symbioses has always been the remarkable cooperation between the plant-microbe partners and their potential in agriculture. By contrast, phytopathological studies have inevitably focused on the interest in preventing or attenuating pathogenic attacks on crop cultures. By and large, the consequence of this has been a focus of interest on the very early responses of plants to pathogens, as opposed to the establishment and functioning of the symbiotic structures resulting from associations with organisms such as rhizobia and AM fungi. On the other hand, dwelling upon symbionts has promoted the investigation of its cellular aspects, whereas immunity, defense, susceptibility and resistance to pathogens have prioritized investigations in this field. A survey of recent literature suggests that the gaps in our knowledge are being progressively filled, and a common view is now emerging.

\section{A SURVEY OF EARLY PLANT-CELL RESPONSES}

A critical summary of the cellular responses that take place during the crucial period between the perception of a microorganism (either via its secreted elicitors or upon direct contact) and the determination of the fate of the interaction is presented in the following sections. For the sake of lexical uniformity, the term "guest" will often be used with reference to any microorganism that attempts plant cell penetration.

Online booking: host cell prealert.

Chemistry is the language of cells and plant-interacting microbes are no exception. Any plant-microbe interaction in which chemical signaling has been investigated thoroughly has revealed the existence of a precise molecular dialogue prior to and during direct cell-to-cell contact (Glazebrook 2005; Geurts et al. 2005; Paszkowsky 2006a). Pathogenic fungal effector molecules are reported to trigger signaling cascades (Zhang and Klessig 2001), gene activation (Schenk et al. 2000), the release of defense-related molecules, and systemic reactions (Grant and Lamb 2006). Unfortunately, these investigations have rarely considered subcellular reactions as part of the responses to the effectors tested. A remarkable exception is the investigation by Binet and associates (2001), who observed microtubule disruption in parsley cultured cells exposed to soluble elicitors from Phytophthora cryptogea. This might suggest that responses to diffusible elicitors may involve cytoplasm organization more often than thought, although a clear picture of this is not yet possible.

In the field of symbioses, root nodulation is the most-studied system from this point of view (Gage 2004). In this case, iso- 
lated chemical signals released by rhizobia, the so-called Nod factors (Truchet et al. 1991), induce a number of rapid molecular or cellular responses in root hairs of compatible plant species, including the activation of specific intracellular signaling pathways leading to gene activation, (Lohar et al. 2006; Oldroyd and Downie 2004). Additional later responses to Nod factors include the initiation of nodule organogenesis in the inner cortex (Timmers et al. 1999). In the early 1990's, Heidstra and coworkers (1994) described the swelling of root-hair tips exposed to a Nod factor solution, later correlated with a transient fragmentation and reorganization of the apical cytoskeleton (Cárdenas et al. 1998; de Ruijter et al. 1999; Vassileva et al. 2005). These alterations of hair-cell organization may, however, be the result of the "unnatural" exposure of the whole hair surface to Nod factor solutions. More recently, it has been shown that spot applications of nanodrops of Nod-factor solutions to one side of a growing root-hair tip rapidly reorients its apical growth without swelling (Esseling et al. 2003), and it is currently thought that this directional response mimics the root-hair curling caused by sustained contact with attached rhizobia.

Unfortunately, chemical signals released from AM fungi have not yet been isolated. Nevertheless, a few effects of such signals are known. The activation of early nodulin gene expression (Kosuta et al. 2003) and signal transduction-related gene expression (Weidmann et al. 2004) has been reported in the presence of permeable membranes that block direct fungal contact with the root. In addition, Olah and associates (2005) described an increase in the frequency of root branching in response to diffusible AM fungal factors, although it is unclear whether the same molecules are involved in these different host responses.

Variations in cytosolic $\mathrm{Ca}^{2+}$ concentration, a widespread intracellular signal (Sanders et al. 2002), have also been identified in pathogenic and symbiotic interactions. Several pathogenic fungi elicit extremely specific variations of $\mathrm{Ca}^{2+}$ concentration over time (Lecourieux et al. 2006).

An apparently more complex process rules the interaction with rhizobia, in which, after a very rapid $\mathrm{Ca}^{2+}$ influx, a precise number of rapid and repeated oscillations (spiking) in the $\mathrm{Ca}^{2+}$ concentration (Miwa et al. 2006) is needed to initiate gene regulation.

Navazio and coworkers (2007) have recently reported a characteristic transient increase in cytosolic calcium concentration in soybean cultured cells expressing aequorin and exposed to AM fungal exudates. While awaiting confirmation in planta, this is the first evidence that calcium mediates the interpretation of AM fungal signals by compatible plant cells, whereas pathogen-related reactions such as reactive oxygen species production and programmed cell death are not set off. Unfortunately, in all these experiments no direct correlation has been made with potential cytoplasmic reorganization in the target cells, although several organelles, such as the endoplasmic reticulum (ER), the nuclear envelope, and the vacuole, are proposed as intracellular $\mathrm{Ca}^{2+}$ reservoirs (Sanders et al. 2002).

Taken together, such observations support the idea that diffusible guest signals induce a first level of basic plant responses, ranging from a general prealert to more obvious morphological responses at a molecular, cellular, and organ level. Nevertheless, a more comprehensive picture is still incomplete, due to the diverse aspects investigated in each interaction, which cannot always be directly compared.

\section{Boarding gate: direct cell contact.}

Biotrophy, literally live feeding, requires the preservation of host-cell viability as a basic feature. Plant cell entry, therefore, represents a crucial event in the context of the compatibility of biotrophic interactions (O'Connell and Panstruga 2006). Avoiding aggressive strategies is essential, especially for obligate biotrophs, which have abandoned part of their basic metabolic capabilities in favor of a plant-dependent life style (Spanu 2006).

Plant nonhost resistance strategies represent the first line of defense against invading microbes (Jones and Dangl 2006). They consist of multiple layers of defense responses, as elegantly demonstrated in the interaction between Arabidopsis and pathogenic filamentous microbes (Collins et al. 2003; Lipka et al. 2005). Waxy cuticles and preformed antimicrobials constitute the nonspecific background of plant immunity (Grennan 2006). Microbes that pass this barrier and attempt cell penetration can then be blocked at the plant surface by the formation of cell-wall appositions or papillae (Koh and Somerville 2006). The genetic dissection of this active nonhost resistance has identified the role of genes such as PEN1 (a syntaxin), PEN2 (a glycosyl hydrolase), or PEN3 (an ATP-binding cassette transporter). The mutation of each one of these genes, in fact, increases the number of successful penetrations by nonadapted pathogens (Collins et al. 2003; Lipka et al. 2005).

From the point of view of subcellular responses, the first visible reaction is a rapid translocation of the cytosol and subcellular elements to the contact site. This is called cytoplasmic aggregation (CA) and has been described in many plant interactions (Takemoto and Hardham 2004). CA results from the establishment of a striking asymmetry within the cell (Schmelzer 2002) through rapid site-directed cytoplasmic streaming (Heath et al. 1997). The use of actin depolymerizing drugs has shown that CA depends primarily on the action of the actin cytoskeleton (Hazen and Bushnell 1983; Tomiyama et al. 1982). More recently, cytochemical and GFP-labeling of actin microfilaments have revealed their radial organization around the penetration site in many plant-pathogen interactions (Takemoto and Hardham 2004). Microtubules, on the other hand, show more heterogeneous patterns. In barley and flax, they form radial arrays around the contact site with rust fungi (Kobayashi et al. 1994). Oomycetes induce local microtubule depolymerization in the vicinity of the contact area in soybean (Cahill et al. 2002), whereas, in Arabidopsis, they cause the specific disorganization of bundles pointing towards the contact site, leading to the appearance of circular arrays of microtubules centered on the contact site and extending over several adjacent cells (Takemoto et al. 2003).

Most organelles assemble at the potential infection site, where they contribute to an intense secretory activity (ThordallChristensen 2003), reinforcing the wall with compounds that improve its resistance to the chemical and physical attack directed by the pathogen (Zeyen et al. 2002). Cell-wall appositions, or papillae, develop around and in front of fungal appressoria, intercellular hyphae, and penetration pegs (Aist 1976). The secretion of antifungal compounds has been proposed by Stein and colleagues (2006), who described the accumulation of an ATP-binding cassette transporter (PEN3) underneath and around developing penetration pegs of a powdery mildew.

When cell-wall appositions are not sufficient to arrest noncompatible pathogens or their effectors reach the cytoplasm (O'Connell and Panstruga 2006), a second line of defense can be initiated. Specific receptors trigger signaling cascades that program cell death in the context of the so-called hypersensitive response (Dangl and Jones 2001). The invader is thus surrounded by a hostile environment that rapidly leads to the death of the microbe.

Compatible biotrophic pathogens have evolved a way to elude basal defense in their susceptible hosts (Catanzariti et al. 2006). This happens when virulence effectors produced by the 
pathogen do not match the plant receptors encoded by resistance genes. This matching is the core of the so-called genefor-gene paradigm that rules the world of plant pathology (Glazebrook 2005).

Cytoplasmic aggregation and cell-wall appositions in this case do not block the pathogens, which breach the cell wall and reach the cell lumen. Biotrophic intracellular growth initiates within the CA area, in which secretory activities have already led to papilla formation (Assaad et al. 2004). Similar processes can now be dedicated to membrane proliferation leading to the encapsulation of the invader in a membranous sheath.

Early cell responses to symbionts are at least as delicate as those to pathogens, since a tightly coordinated series of events is essential to bring the guest safely inside host tissues.

While not all nitrogen-fixing symbiotic bacteria colonize their hosts via root hairs, this is the model for which the largest amount of information is available in relation to host cellular responses leading to infection. The modification of root-hair growth, described in response to Nod factors, becomes maximal after the adhesion of just one single bacterium. Root-hair tip growth is reoriented in a continuous curl until a small number of bacteria are entrapped among its coils (Callaham and Torrey 1981). Growing root hairs typically have a large accumulation of cytoplasm at the apex. Dense arrays of microtubules and microfilaments connect the hair tip to the nucleus, which is positioned at a fixed distance behind the growing tip (Ketelaar and Emons 2001). As in pollen tubes and hyphae, the cytoplasm in the growing tip is packed with all the elements of the secretory machinery, such as ER and Golgi bodies. Transgolgi vesicles flow along the cytoskeletal cables as far as the tip area, at which they fuse with the plasma membrane and provide the growing wall with new materials (Miller et al. 1997). Symbiont contact unbalances this dynamic process. The cytoskeleton changes its focus from the hair tip to the nearby area in which bacteria are bound. As a consequence, the secretory vesicles are redirected and rectilinear apical growth becomes curvilinear (Gage 2004).

Once the bacteria are entrapped within the curl, a major alteration of the root-hair development initiates with secretory activity focused towards the center of the curl. As a result, plasma membrane proliferation forms an invagination that contains apoplastic materials and protrudes inside the cell lumen. Local cell-wall degradation at the site of invagination has been reported, although whether this is caused by plant or bacterial enzymes remains unclear (Gage 2004). This is the initiation of the so-called infection thread (IT), which will guide the endosymbiont deep into the root cortex towards the developing nodule, its new home. Interestingly, Nod factors alone cannot trigger IT initiation (Fraysse et al. 2003; Weerasinghe et al. 2003), which depends on the presence of the intact bacterium. Bacterial exopolysaccharides (Pellock et al. 2000) and their derivatives (Staehelin et al. 2006) appear to be essential for successful infection.

A large column of streaming cytoplasm connects the nucleus to the growing IT, and dense cytoskeletal elements have been identified within this column (Timmers et al. 1999), which likely direct this specialized secretion. The distance between the IT apex and the nucleus remains constant during IT growth, until the trichoblast inner wall is reached and bacteria are delivered to the outermost cortical cell. In turn, the underlying cortical cells have already organized the so-called preinfection thread, a string of transvacuolar cytoplasmic columns that anticipate the route of the IT towards the nodule primordium (van Brussel et al. 1992).

Although AM fungi are also known to colonize roots in a variety of ways, partly mirroring the anatomical diversity of their hosts, the most-studied models involve their penetration through epidermal cells. A few days after spore germination in the soil, hyphae adhere to the root epidermis through swollen hyphal branches. These are commonly referred to as "appressoria" (Bonfante 1984), although analogous structures are usually called "hyphopodia" by plant pathologists (Bastmeyer et al. 2002). True appressoria are typically smaller, produced shortly after germination, and show a thick melanized wall. In this review, we prefer to use the term "hyphopodium" in order to have a common language.

Cytological studies (Bonfante et al. 2000) and, more recently, in vivo observations based on GFP intracellular tags (Genre et al. 2005) have provided extensive information on epidermal cell reorganization before and after AM fungal penetration. In this case the whole cell is also dramatically reorganized. The development of a hyphopodium on the surface rapidly stimulates the movement of the nucleus, a mass of cytoplasm, large patches of ER, Golgi complexes, and mitochondria towards the contact point (Genre et al. 2005; P. Bonfante, unpublished). This is mirrored by an equally dramatic reorganization of the cytoskeleton. Microtubules assemble into dense arrays below the contact point, at which actin filaments are also oriented, eventually becoming organized into a radial pattern. Subsequently, the nucleus moves back across the cell, toward the root cortex. A large column of cytoplasm, packed with cytoskeleton, ER, Golgi bodies, mitochondria, and with a central thread rich in membrane (Genre et al. 2005) and secretory vesicles (Genre et al. 2005; P. Bonfante, unpublished) assembles between the nucleus and the contact point. This assembly has been described as the prepenetration apparatus (PPA), and its development proceeds until the whole cell has been traversed. The fungus then begins to penetrate the epidermal cell lumen and follows exactly the track laid down by the PPA, until the intracellular hypha is within an apoplastic channel, lined by an invagination of the host plasma membrane.

These observations show quite clearly how direct contact between the guest and the host is a pivotal event in biotrophic interactions. Compared with the precontact phase, the intensity of the plant response is significantly increased as soon as the microorganism adheres to the cell surface. The triggering of these major rearrangements is most likely mediated by effector molecules produced by the biotroph (Birch et al. 2006; Catanzariti et al. 2006; Hubber et al. 2007), although they have not yet been identified in all plant guests. This can be due either to the contact with exposed effectors on the surface of the guest cells or to their secretion together with adhesive substances. Another possibility is that the same molecules acting as longdistance diffusible signals also play a role upon direct contact. In this case, their localized production in higher concentrations could be responsible for the enhanced host responses.

\section{Intracellular lodging.}

Irrespective of the type of host cell, all plant intracellular biotrophic guests end up in a specialized membrane-delimited compartment (Smith 1979), which is padded with amorphous plant cell-wall materials and is the site of intense nutrient trafficking. The composition of these interfaces has been investigated thoroughly and the results once again reveal morphological similarities and functional differences. While rhizobia are released at the end of the IT within isolated vesicles (Gage 2004), fungi are always ensheathed by a membrane that is continuous with the plasmalemma. However, this physical connection, granting plant cell integrity, may or may not mirror functional homogeneity. In the case of pathogenic fungi, perihaustorial membranes are known to be functionally distinct from the rest of the plasma membrane, as witnessed by the different composition in proteins and lipids (Assaad et al. 2004; Bhat et al. 2005). This originates from selective vesicle 
fusion and is maintained thanks to the existence of a specialized membrane domain that tightly surrounds the haustorium neck and hampers the free exchange of membrane elements (Koh et al. 2005). Analogous neck complexes have never been described in cells traversed by AM hyphae or the IT. Nevertheless, both a phosphate transporter (Harrison et al. 2002) and an $\mathrm{H}^{+}$-ATPase (Gianinazzi-Pearson et al. 2000) specifically localize to the periarbuscular membrane, suggesting that this particular domain is at least functionally distinct. The composition of interfacial matrixes is apparently more uniform (Patriarca et al. 2004), reminiscent of the plant primary cell wall (Balestrini and Bonfante 2005; Stark-Urnau and Mendgen 1995). Its amorphous texture is thought to originate from the presence of cell-wall-loosening proteins that prevent the formation of cross-links between the cell-wall components (Balestrini et al. 2005; Maldonado-Mendoza et al. 2005), although in the case of rhizobia, the IT matrix is described as rather rigid (Brewin 2004). One aspect that still needs to be explored thoroughly is the role played by fungal enzymes.

In conclusion, the overall morphological similarity shown by the intracellular accommodation structures for biotrophic organisms actually only mirrors one feature of their functions, the preservation of host-cell integrity. This necessity is, in fact, common to all interactions. Conversely, the nutritional strategy and the specific exchanges that characterize each biotroph directly influence the composition and function of the surrounding interface.

\section{COMPARATIVE ANALYSIS OF HOST CELL RESPONSES}

\section{The cell-wall membrane-cytoskeleton continuum.}

Comparing early cell responses, it would be tempting to conclude that, no matter what microorganism is contacting a plant cell, the same initial mechanism is evoked (Paszkowsky 2006b). The cytoskeleton reorganizes around the contact point (Takemoto and Hardham 2004), leading to CA, a dramatic polarization of the contacted cell (Schmelzer 2002), which initiates novel secretory activities.

The outcomes of these apparently similar starting points are very divergent. On the one hand, internalization of the guest will improve plant nutrition in the case of symbiotic interactions, and on the other, pathogens can damage, parasitize, and potentially kill the plant. The selective pressure is obviously contrasting; plants that succeed are those that are the most effective in keeping pathogens out and taking symbionts in. It would, therefore, be misleading to interpret the accumulation of cytoplasm underneath the guest as a homogeneous response (Fig. 1). The term "cytoplasmic aggregation" describes a raw morphological modification of the cytosol but does not provide true information about the precise mechanisms that are acting. In the case of pathogenic interactions, biotrophy is achieved at the end of a long process. Secretion is initially directed to reinforce the cell wall and later to preserve plasma membrane integrity, therefore preventing the invaded cell from being directly damaged. It is interesting to note that CA and papilla formation may last for days after pathogen adhesion. As an example, the hemibiotroph Colletotrichum trifolii penetrates Medicago truncatula epidermal cells only $48 \mathrm{~h}$ after contact (Torregrosa et al. 2004). On the other hand, the entry of the AM fungus Gigaspora gigantea into the same host usually takes place within 7 to $8 \mathrm{~h}$ (Genre et al. 2005). It would be useful in this context to know the precise timing of rhizobial infection. However, although IT are initiated only 36 to $48 \mathrm{~h}$ after inoculation (D. Barker, personal communication), this period includes bacterial proliferation, adhesion, and root-hair curling. Thus, cell reactions induced by symbionts may be lim- ited to the direct synthesis of an intracellular compartment and not include those initially induced by pathogens. This would imply that symbiont and pathogen are recognized before or during direct cell contact through specific signals, corroborating the hypothesis of plant prealert mechanisms.

Whenever a guest contacts the cell wall, the host nucleus reaches the contact site and remains in position, with constant fine adjustments (Heath et al. 1997). This can be interpreted as a general defense response. Plant nuclei have been reported to be positioned in front of the point of contact with bacteria, fungi, and nematodes (Weerasinghe et al. 2005), as well as physical stimulators such as metal rods or microneedles (GusMayer et al. 1998). In addition, tissue wounding rapidly causes nuclei to move in the direction of the wound in all neighboring cells (Jaffe et al. 2002). Nuclear movement in response to a threat to cell integrity merits discussion. First of all, the nucleus does not move alone; ER, in continuity with the nuclear envelope, Golgi bodies, plastids, mitochondria, and the cell's largest pool of cytoplasm all surround the nucleus. Each of these organelles is responsible for a specific component of the cell reaction. Concentrating them all at one site possibly shortens the response time to the stimulus, in a cell in which communication and transport must circumvent the huge central vacuole. Thanks to local repositioning, signal transduction pathways may activate gene expression more rapidly and transcripts can be concentrated at the site where they are translated into key response proteins (Rodriguez et al. 2006). The proteins themselves may be rapidly modified in ER and Golgi cisternae and finally released exactly where necessary.

Lastly, from an evolutionary point of view, the cell mechanisms set in motion by these plant-microbe interactions are probably related to a more archaic cellular process. Focused secretion, cytoskeleton mobilization, nuclear movement, cytoplasmic strands crossing the vacuole-all of these responses are directly involved in cell division, thus supporting the hypothesis that basic cell processes such as cytokinesis may have been recruited and modulated as the need arose to reinforce the cell wall or accommodate a biotroph within the cell lumen.

\section{Polarizing the host cell.}

Several hypotheses have been postulated concerning the way a cell perceives contact with a potential guest. Surface effector molecules (Hubber et al. 2007) are known to set off intracellular signaling cascades, although these are supposed to amplify and spread information throughout the whole cell, possibly hampering a precise tagging of the contact site, which on the contrary, appears to be a pivotal feature. Mechanical forces are exerted on the host cell wall by fungal adhesion structures (Bastmeyer et al. 2002). Their perception is hypothesized to trigger signaling cascades, based on the existence of tension-dependent membrane channels (Jaffe et al. 2002). These would allow an influx of $\mathrm{Ca}^{2+}$ when the plant membrane is stretched by the deformation of the cell wall. Other hypothetical mechanisms can be proposed that involve the organization of specialized membrane domains (Bhat et al. 2005) that label the contact site, and focal accumulation of membrane-bound proteins has been demonstrated by yellow fluorescent protein tagging (Assaad et al. 2004). Another intriguing possibility is suggested by the existence of a close physical connection between the cytoskeleton and cell walls (Schmelzer 2002), which extends throughout the cell volume and the neighboring cells. Such mechanistic models, known in physics as tensegrity (Ingber 1998), imply that local modifications rapidly alter the whole system, and they are occasionally proposed to explain plant biological processes. These could contribute towards the coding of the topological information that rules cytoplasmic aggregation, possibly in synergy with the other proposed mechanisms. 
The asymmetry or polarization of the cytoplasm during early stages of plant-microbe interactions is a remarkable reorganization for differentiated plant cells and reflects the new functional status acquired by the cell. Such focal organization appears to be a crucial element of the plant response, although the mechanisms by which this is obtained are still far from being understood.

Defining cytoplasmic aggregation.

In all the CA-like responses described so far, organelles have always been described as accumulating at a particular site, thus implying their migration from elsewhere in the cell. This inter- pretation might, however, not reflect the true situation. CA was first characterized through classic cytological transmission electron microscopy (TEM) observations, immunolabeling, and immunofluorescence. However, more recent in vivo studies suggest an alternative interpretation of this body of observations based on fixed biological material. Whereas the nucleus is repositioned in association with a mass of cytoplasm, other organelles behave differently. For example, the displacement of ER elements from the whole cytosol towards the contact site would deprive the rest of the cell of essential ER. However, when the organization of ER is studied in its three-dimensional complexity through in vivo confocal microscopy (Fig. 2), it

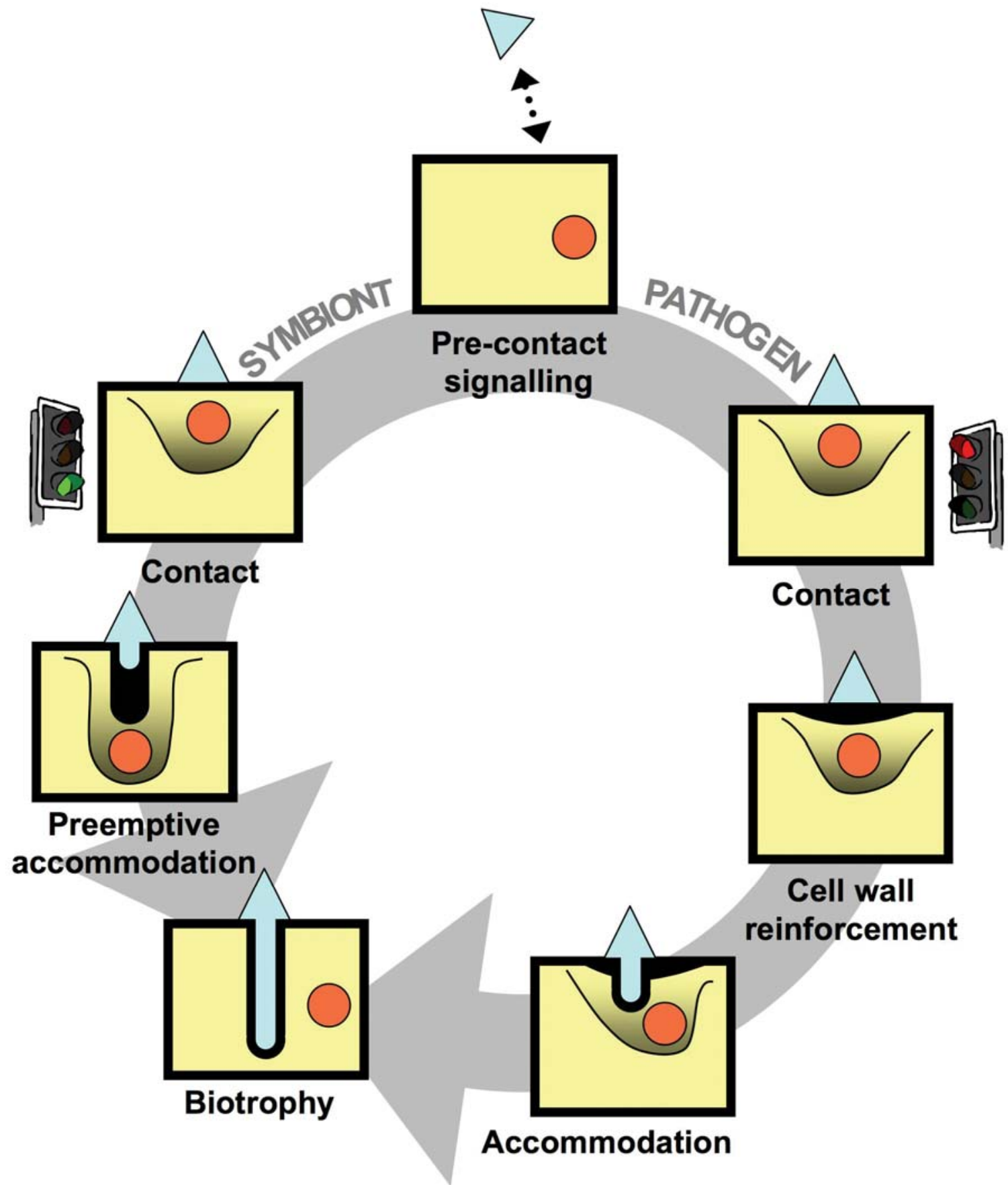

Fig. 1. Hypothetical alternative routes to biotrophy for plant endocellular symbionts and pathogens. Precontact signaling contributes to the recognition of the guest (white triangle) as a symbiont or a pathogen. Direct contact then triggers localized secretion through cytoplasmic aggregation, but while in the first case this leads directly to preemptive assembly of an intracellular apoplastic compartment to host the symbiont (arbuscular mycorrhizal fungi or rhizobia), in the second case, secretion is initially aimed at reinforcing the cell wall and only secondly at accommodating the pathogen and preserving host-cell integrity. A biotrophic state is eventually reached in both cases, although the route for symbionts is shorter. 

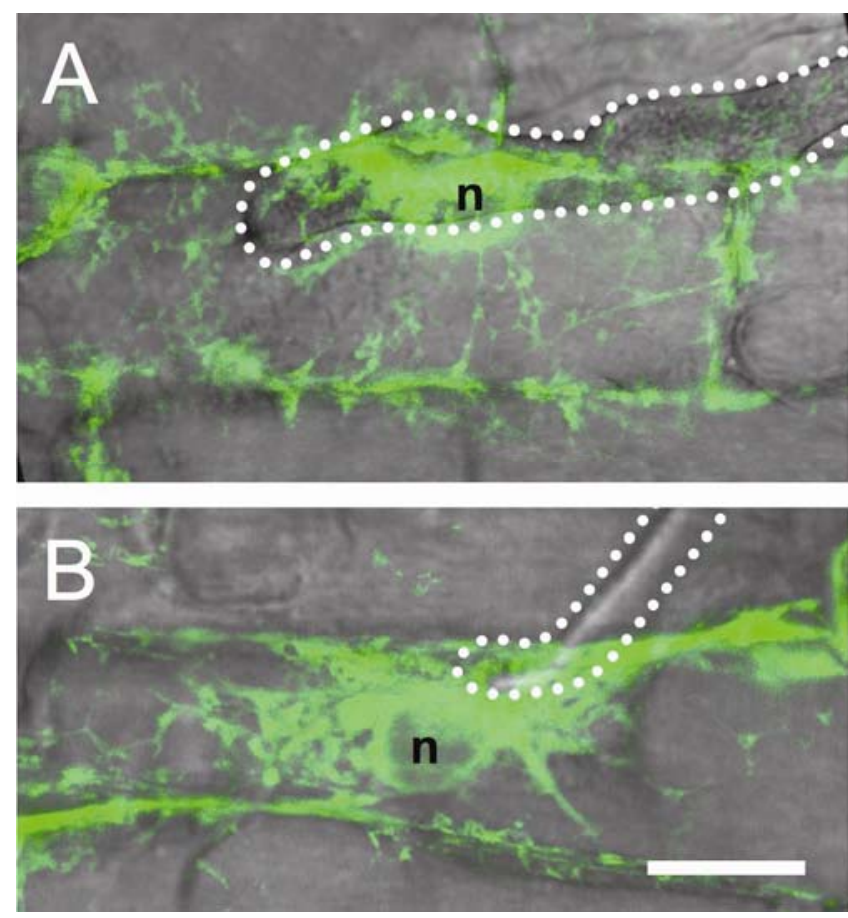

Fig. 2. Confocal micrographs showing the proliferation of endoplasmic reticulum (ER) in root epidermal cells beneath $\mathbf{A}$, a hyphopodium of the arbuscular mycorrhizal fungus Gigaspora gigantea and $\mathbf{B}$, the hemibiotrophic pathogen Colletotrichum trifolii. The ER (green) is labeled with GFPHDEL, expressed in Medicago truncatula root-organ cultures. Transmitted light images are overlayed in grayscale. Bar $=15 \mu \mathrm{m}$.

appears clear that its distribution in the cell remains constant outside of the CA area, in which the cisternae are thicker, larger, and more densely interconnected (Koh et al. 2005; Genre et al. 2005). This suggests a local enrichment or expansion of the ER, possibly related to intense protein synthesis and secretion. Similarly, Golgi complexes are usually abundant in TEM micrographs within the CA. Recent observations with fluorescent protein tags have revealed that these organelles move constantly around the cell, running along actin cables (Boevink et al. 1998), and stop more often in the vicinity of the contact site (Takemoto et al. 2003), which can be correlated with intense local secretory activity (Nebenführ et al. 1999). Peroxisomes also abound in the area, and Koh and coworkers (2005) have observed their movement towards the penetration site. At the same time, these authors show that the peroxisome density outside the CA area remains approximately constant. Such short-lived organelles may therefore proliferate in situ. Taken together, these data offer an alternative vision of cytoplasmic aggregation as a much more dynamic and complex process than the simple migration of intracellular components towards the site of microbial contact.

\section{CONCLUSIONS}

Biotrophy requires an extremely precise coordination between guest and host developmental programs. The biotroph could irreversibly damage the host membrane if this were not so, and its development must be strictly controlled by the plant. The host cell prepares a specialized compartment in coordination with the guest's developmental program. From this point of view, it is worth noting that both pathogens and symbionts stop growing upon adhesion to the plant surface and traverse the cell wall only after secretory machinery has been established by the host.

Hosting single bacterial cells within membrane vesicles can be considered as a remarkable evolutionary modification of en- docytosis (Margulis 1970). Confining an organism as complex as a fungus in the living cells of preexisting tissues appears to be an even harder job. Intracellular hyphae can occupy most of the cell lumen, grow at high rates, keep their connection within and outside the plant, and develop vigorous osmotic pressure-a rather hard guest to deal with, even when beneficial.

Comparisons of early cell responses during plant biotrophic interactions reveal a few surprises. Hosting an alien organism within a cell is the most intimate relationship that a plant can develop and clearly implies the need to preserve cell integrity. The variability among plant interacting organisms and their different nutritional strategies results in different types of intracellular accommodation and reveals the full potential of plants to interact with their biotic environment.

\section{ACKNOWLEDGMENTS}

We would like to thank D. Barker (Laboratoire Interactions Plantes Micro-organismes, Castanet Tolosan, France) for stimulating discussion and for critically revising the manuscript, and to R. O'Connell (Max Plank Institut für Züchtungsforschung, Köln, Germany) for kindly providing C. trifolii. Support for P. Bonfante was provided by the following projects: PRIN 2006, CNR Biodiversity Project, University grant (60\%), UE INTEGRAL 505227 and CEBIOVEM.

\section{LITERATURE CITED}

Aist, J. R. 1976. Papillae and related wound plugs of plant cells. Annu. Rev. Phytopathol. 14:145-163.

Assaad, F. F., Qiu, J. L., Youngs, H., Ehrhardt, D., Zimmerli, L., Kalde, M., Wanner, G., Peck, S. C., Edwards, H., Ramonell, K., Somerville, C R., and Thordal-Christensen, H. 2004. The PEN1 syntaxin defines a novel cellular compartment upon fungal attack and is required for the timely assembly of papillae. Mol. Biol. Cell 15:5118-5129.

Balestrini, R., and Bonfante, P. 2005. The interface compartment in arbuscular mycorrhizae: A special type of plant cell wall? Plant Biosyst. 139:8-15.

Balestrini, R., Cosgrove, D. J., and Bonfante, P. 2005. Differential location of alpha-expansin proteins during the accommodation of root cells to an arbuscular mycorrhizal fungus. Planta 220:889-899.

Bastmeyer, M., Deising, H. B., and Bechinger, C. 2002. Force exertion in fungal infection. Ann. Rev. Biophys. Biomol. Struct. 31:321-41.

Bhat, R. A., and Panstruga, R. 2005. Lipid rafts in plants. Planta 223:5-19.

Bhat, R. A., Miklis, M., Schmelzer, E., Schulze-Lefert, P., and Panstruga, R. 2005. Recruitment and interaction dynamics of plant penetration resistance components in a plasma membrane microdomain. Proc. Natl. Acad. Sci. U.S.A. 102:3135-3140.

Binet, M. N., Humbert, C., Lecourieux, D., Vantard, M., and Pugin, A. 2001. Disruption of microtubular cytoskeleton induced by cryptogein, an elicitor of hypersensitive response in tobacco cells. Plant Physiol. 125:564-572.

Birch, P. R. J., Rehmany, A. P., Pritchard, L., Kamoun, S., and Beynon, J. L. 2006. Trafficking arms: Oomycete effectors enter host plant cells Trends Microbiol. 14:8-11.

Boevink, P., Oparka, K., Santa Cruz, S., Martin, B., Batteridge, A., and Hawes, C. 1998. Stacks on tracks: The plant Golgi apparatus traffics on an active actin/ER network. Plant J. 15:441-447.

Bonfante, P. 1984. Anatomy and morphology of VA mycorrhizae. Pages 533 in: VA Mycorrhizae. C. L. Powell and D. J. Bagyaraj, eds. CRC Press, Boca Raton, FL, U.S.A.

Bonfante, P., Genre, A., Faccio, A., Martini, I., Schauser, L., Stougaard, J. Webb, J., and Parniske, M. 2000. The Lotus japonicus LjSym4 gene is required for the successful symbiotic infection of root epidermal cells Mol. Plant-Microbe Interact. 13:1109-1120.

Brandizzi, F., Fricker, M., and Hawes C. 2002. A greener world: The revolution in plant bioimaging. Nat. Rev. 3:520-530.

Brewin, N. J. 2004. Plant cell wall remodeling in the rhizobium-legume symbiosis. Crit. Rev. Plant Sci. 23:293-316.

Cahill, D., Rookes, J., Michalczyk, A., McDonald, K., and Drake, A. 2002. Microtubule dynamics in compatible and incompatible interactions of soybean hypocotyl cells with Phytophthora sojae. Plant Pathol. 51:629640.

Callaham, D. A., and Torrey, J. G. 1981. The structural basis for infection of root hairs of Trifolium repens by Rhizobium. Can. J. Bot. 59:16471664.

Cárdenas, L., Vidali, L., Dominguez, J., Perez, H., Sanchez, F., Hepler, P. 
K., and Quinto, C. 1998. Rearrangement of actin microfilaments in plant root hairs responding to Rhizobium etli nodulation signals. Plant Physiol. 116:871-877.

Catanzariti, A. M., Dodds, P. N., Lawrence, G. J., Ayliffe, M. A., and Ellisa, J. G. 2006. Haustorially expressed secreted proteins from flax rust are highly enriched for avirulence elicitors. Plant Cell 18:243-256.

Collins, N. C., Thordal-Christensen, H., Lipka, V., Bau, S., Kombrink, E., Qiu, J. L., Huckelhoven, R., Stein, M., Freialdenhoven, A., Somerville, S. C., and Schulze-Lefert, P. 2003. SNARE-protein-mediated disease resistance at the plant cell wall. Nature 425:973-977.

Dangl, J. L., and Jones, J. D. G. 2001. Plant pathogens and integrated defence responses to infection. Nature 411:826-833.

de Ruijter, N. C. A., Bisseling, T., and Emons, A. M. C. 1999. Rhizobium Nod factors induce an increase in sub-apical fine bundles of actin filaments in Vicia sativa root hairs within minutes. Mol. Plant-Microbe Interact. 12:829-832.

Dhanoa, P. K., Sinclair, A. M., Mullen, R. T., and Mathur, J. 2006. Illuminating subcellular structures and dynamics in plants: A fluorescent protein toolbox. Can. J. Bot. 84:515-522.

Esseling, J. J., Lhuissier, F. G., and Emons, A. M. 2003. Nod factorinduced root hair curling: Continuous polar growth towards the point of Nod factor application. Plant Physiol. 132:1982-1988.

Fraysse, N., Couderc, F., and Poinsot, V. 2003. Surface polysaccharide involvement in establishing the rhizobium-legume symbiosis. Eur. J. Biochem. 270:1365-1380.

Gage, D. J. 2004. Infection and invasion of roots by symbiotic, nitrogenfixing rhizobia during nodulation of temperate legumes. Microbiol. Mol. Biol. Rev. 68:280-300.

Genre, A., Chabaud, M., Timmers, T., Bonfante, P., and Barker, D. G. 2005. Arbuscular mycorrhizal fungi elicit a novel intracellular apparatus in Medicago truncatula root epidermal cells before infection. Plant Cell 17:3489-3499.

Geurts, R., Fedorova, E., and Bisseling, T. 2005. Nod factor signaling genes and their function in the early stages of Rhizobium infection. Curr. Opin. Plant Biol. 8:346-352.

Gianinazzi-Pearson, V., Arnould, C., Oufattole, M., Arango, M., and Gianinazzi, S. 2000. Differential activation of $\mathrm{H}^{+}$-ATPase genes by an arbuscular mycorrhizal fungus in root cells of transgenic tobacco. Planta 211:609-613.

Glazebrook, J. 2005. Contrasting mechanisms of defense against biotrophic and necrotrophic pathogens. Annu. Rev. Phytopathol. 43:205-27.

Grant, M., and Lamb, C. 2006. Systemic immunity. Curr. Opin. Plant Biol. 9:414-420.

Grennan, A. K. 2006. Plant response to bacterial pathogens: Overlap between innate and gene-for-gene defense response. Plant Physiol. 142:809-811.

Gus-Mayer, S., Naton, B., Hahlbrock, K., and Schmelzer, E. 1998. Local mechanical stimulation induces components of the pathogen defense response in parsley. Proc. Natl. Acad. Sci. U.S.A. 95:8398-8403.

Harrison, M J., Dewbre, G. R., and Liu, J. Y. 2002. A phosphate transporter from Medicago truncatula involved in the acquisition of phosphate released by arbuscular mycorrhizal fungi. Plant Cell 14:24132429.

Hazen, B. E., and Bushnell, W. R. 1983. Inhibition of the hypersensitive reaction in barley to powdery mildew by heat shock and cytochalasin B. Physiol. Plant. Pathol. 23:421-438.

Heath, M. C., Nimchuk, Z. L., and Xu, H. 1997. Plant nuclear migrations as indicators of critical interactions between resistant or susceptible cowpea epidermal cells and invasion hyphae of the cowpea rust fungus. New Phytol. 135:689-700.

Heidstra, R., Geurts, R., Franssen, H., Spaink, H. P., Van Kammen, A., and Bisseling, T. 1994. Root hair deformation activity of nodulation factors and their fate on Vicia sativa. Plant Physiol. 105:787-797.

Hubber, A. M., Sullivan, J. T., and Ronson, C. W. 2007. Symbiosisinduced cascade regulation of the Mesorhizobium loti R7A VirB/D4 type IV secretion system. Mol. Plant-Microbe Interact. 20:255-261.

Ingber, D. E. 1998. The architecture of life. Sci. Am. 278:30-39.

Jaffe, M. J., Leopold, A. C., and Staples, R. C. 2002. Thigmo responses in plants and fungi. Am. J. Bot. 89:375-382.

Jones, J. D. G., and Dangl, J. L. 2006. The plant immune system. Nature 444:323-329.

Ketelaar, T., and Emons, A. M. C. 2001. The cytoskeleton in plant cell growth: Lessons from root hairs. New Phytol. 152:409-418.

Kobayashi, I., Kobayashi, Y., and Hardham, A. R. 1994. Dynamic reorganization of microtubules and microfilaments in flax cells during the resistance response to flax rust infection. Planta 195:237-247.

Koh, S., and Somerville, S. 2006. Show and tell: Cell biology of pathogen invasion. Curr. Opin. Plant Biol. 9:406-413.

Koh, S., André, A., Edwards, H., Ehrhardt, D., and Somerville, S. 2005. Arabidopsis thaliana subcellular responses to compatible Erysiphe cichoracearum infections. Plant J. 44:516-529.

Kosuta, S., Chabaud, M., Lougnon, G., Gough, C., Dénarie, J., Barker, D. G., and Bécard, G. 2003. A diffusible factor from arbuscular mycorrhizal fungi induces symbiosis-specific MtENOD11 expression in roots of Medicago truncatula. Plant Physiol. 131:1-11.

Lecourieux, D., Ranjeva, R., and Pugin, A. 2006. Calcium in plant defence-signalling pathways. New Phytol. 171:249-269.

Lipka, V., Dittgen, J., Bednarek, P., Bhat, R., Wiermer, M., Stein, M., Landtag, J., Brandt, W., Rosahl, S., Scheel, D., Llorente, F., Molina, A., Parker, J., Somerville, S., and Schulze-Lefert, P. 2005. Pre- and postinvasion defenses both contribute to nonhost resistance in Arabidopsis. Science 310:1180-1183.

Lohar, D. P., Sharopova, N., Endre, G., Peñuela, S., Samac, D., Town, C. Silverstein, K. A. T., and VandenBosch, K. A. 2006. Transcript analysis of early nodulation events in Medicago truncatula. Plant Physiol. 140:221-234.

Maldonado-Mendoza, I. E., Dewbre, G. R., Blaylock, L., and Harrison, M. J. 2005. Expression of a xyloglucan endotransglucosylase/hydrolase gene, Mt-XTH1, from Medicago truncatula is induced systemically in mycorrhizal roots. Gene 345:191-197.

Margulis, L. 1970 Origin of Eukaryotic Cells. Yale University Press, New Haven, CT, U.S.A.

Miller, D. D., deRuijter, N. C. A., and Emons, A. M. C. 1997. From signal to form: Aspects of the cytoskeleton plasma membrane cell wall continuum in root hair tips. J. Exp. Bot. 48:1881-1896.

Miwa, H., Sun, J., Oldroyd, G. E. D., and Downie, A. J. 2006. Analysis of calcium spiking using a cameleon calcium sensor reveals that nodulation gene expression is regulated by calcium spike number and the developmental status of the cell. Plant J. 48:883-894.

Navazio, L., Moscatiello, R., Genre, A., Novero, M., Baldan, B., Bonfante, and P., Mariani, P. 2007. A diffusible signal from arbuscular mycorrhizal fungi elicits a transient cytosolic calcium elevation in host plant cells. Plant Physiol. 166:673-681.

Nebenführ, A., Gallagher, L. A., Dunahay, T. G., Frohlick, J. A., Mazurkiewicz, A. M., Meehl, J. B., and Staehelin, L. A. 1999. Stopand-go movements of plant Golgi stacks are mediated by the acto-myosin system. Plant Physiol. 121:1127-1142.

O'Connell, R. J., and Panstruga, R. 2006. Tête à tête inside a plant cell: Establishing compatibility between plants and biotrophic fungi and oomycetes. New Phytol. 171:699-718.

Olah, B., Briere, C., Becard, G., Denarie, J., and Gough, C. 2005. Nod factors and a diffusible factor from arbuscular mycorrhizal fungi stimulate lateral root formation in Medicago truncatula via the DMI1/DMI2 signalling pathway. Plant J. 44:195-207.

Oldroyd, G. E. D., and Downie, J. A. 2004. Calcium, kinases and nodulation signalling in legumes. Nat. Rev. 5:566-576.

Oldroyd, G. E. D., and Downie, J. A. 2006. Nuclear calcium changes at the core of symbiosis signalling. Curr. Opin. Plant Biol. 9:351-357.

Parniske, M. 2004. Molecular genetics of the arbuscular mycorrhizal symbiosis. Curr. Opin. Plant Biol. 7:414-421.

Paszkowsky, U. 2006a. A journey through signaling in arbuscular mycorrhizal symbioses. New Phytol. 172 :35-46.

Paszkowski, U. 2006b Mutualism and parasitism: The yin and yang of plant symbioses. Curr. Opin. Plant Biol. 9:364-370.

Patriarca, E. J., Tatè, R., Ferraioli, S., and Iaccarino, M. 2004. Organogenesis of the legume root nodules. Intl. Rev. Cytol. 234:201-262.

Pellock, B. J., Cheng, H., Walker, G. C. 2000. Alfalfa root nodule invasion efficiency is dependent on Sinorhizobium meliloti polysaccharides. J. Bacteriol. 182:4310-4318.

Rodriguez, A. J., Shenoy, S. M., Singer, R. H., and Condeelis, J. 2006. Visualization of mRNA translation in living cells. J. Cell. Biol. 175:6776.

Sanders, D., Pelloux, J., Brownlee, C., and Harper, J. F. 2002. Calcium at the crossroads of signaling. Plant Cell Suppl. 2002:S401-S417.

Schenk, P. M., Kazan, K., Wilson, I., Anderson, J. P., Richmond, T., Somerville, S. T., and Manners, J M. 2000. Coordinated plant defense responses in Arabidopsis revealed by microarray analysis. Proc. Natl. Acad. Sci. U.S.A. 97:11655-11660.

Schmelzer, E. 2002. Cell polarization, a crucial process in fungal defence. Trends Plant Sci. 7:411-415.

Smith, D. C. 1979. From extracellular to intracellular: The establishment of a symbiosis. Pages 1-16 in: The Cell as a Habitat. M. H. Richmond and D. C. Smith, ed., Royal Society Press, London.

Spanu, P. 2006. Why do some fungi give up their freedom and become obligate dependants on their host? New Phytol. 171:447-450.

Staehelin, C., Forsberg, L. S., D’Haeze, W., Gao, M., Carlson, R. W., Xie, Z., Pellock, B J., Jones, K. M., Walker, G C., Streit, W. R., and Broughton, W. J. 2006. Exo-oligosaccharides of Rhizobium sp. strain NGR234 are required for symbiosis with various legumes. J. Bacteriol. 188:6168-6178. 
Stark-Urnau, M., and Mendgen, K. 1995. Sequential deposition of plant glycoproteins and polysaccharides at the host-parasite interface of Uromyces vignae and Vigna sinensis-Evidence for endocytosis and secretion. Protoplasma 186:1-11.

Stein, M., Dittgen, J., Sanchez-Rodriguez, C., Hou, B.H., Molina, A., Schulze-Lefert, P., Lipka, V., and Somerville, S. 2006. Arabidopsis PEN3/PDR8, an ATP binding cassette transporter, contributes to nonhost resistance to inappropriate pathogens that enter by direct penetration. Plant Cell 18:731-746

Takemoto, D., and Hardham, A. R. 2004. The cytoskeleton as a regulator and target of biotic interactions in plants. Plant Physiol. 136:3864-3876.

Takemoto, D., Jones, D. A., and Hardham, A. R. 2003. GFP-tagging of cell components reveals the dynamics of subcellular re-organization in response to infection of Arabidopsis by oomycete pathogens. Plant J. 33:775-792.

Thordal-Christensen, H. 2003. Fresh insights into processes of nonhost resistance. Curr. Opin. Plant Biol. 6:351-357.

Timmers, A. C., Auriac, M. C., and Truchet, G. 1999. Refined analysis of early symbiotic steps of the Rhizobium-Medicago interaction in relationship with microtubular cytoskeleton rearrangements. Development 126:3617-3628

Tomiyama, K., Sato, K., and Doke, N. 1982 Effect of cytochalasin B and colchicine on hypersensitive death of potato cells infected by incompatible race of Phytophthora infestans. Ann. Phytopathol. Soc. Jpn. 48:228-230.

Torregrosa, C., Cluzet, S., Fournier, J., Huguet, T., Gamas, P., Prosperi, J.M., Esquerre-Tugaye, M.-T., Dumas, B., and Jacquet, C. 2004. Cytological, genetic, and molecular analysis to characterize compatible and incompatible interactions between Medicago truncatula and Colletot- richum trifolii. Mol. Plant-Microbe Interact. 17:909-920.

Truchet, G., Roche, P., Lerouge, P., Vasse, J., Camut, S., Debilly, F., Prome, J. C., and Denarie, J. 1991. Sulfated lipo-olligosaccharide sig nals of Rhizobium meliloti elicit root nodule organogenesis in alfalfa. Nature 351:670-673.

van Brussel, A. A. N., Bakhuizen, R., van Spronsen, P. C., Spaink, H. P., Tak, T., Lugtenberg, B. J. J., and Kijne, J. W. 1992. Induction of preinfection thread structures in the leguminous host plant by mitogenic lipo-oligosaccharidess of Rhizobium. Science 257:70-72.

Vassileva, V. N., Kouchi, H., and Ridgea, R. W. 2005. Microtubule dynamics in living root hairs: Transient slowing by lipochitin oligosaccharide nodulation signals. Plant Cell 17:1777-1787.

Weerasinghe, R. R., Collings, D. A., Johannes, E., and Allen, N. S. 2003. The distributional changes and role of microtubules in Nod factor-challenged Medicago sativa root hairs. Planta 218:276-287.

Weerasinghe, R. R., McK Bird, D., and Allen, N. S. 2005. Root-knot nematodes and bacterial Nod factors elicit common signal transduction events in Lotus japonicus. Proc. Natl. Acad. Sci. U.S.A. 102:3147-3152.

Weidmann, S., Sanchez, L., Descombin, J., Chatagnier, O., Gianinazzi, S. and Gianinazzi-Pearson, V. 2004. Fungal elicitation of signal transduction-related plant genes precedes mycorrhiza establishment and requires the dmi3 gene in Medicago truncatula. Mol. Plant-Microbe Interact. 17:1385-1393.

Zeyen, R. J., Carver, T. L. W., and Lyngkjaer, M. F. 2002. Epidermal cell papillae. Pages 107-125. In: The Powdery Mildews: A Comprehensive Treatise. R. R. Belanger, W. R. Bushnell, A. J. Dik, and T. L. W. Carver, eds. American Phytopathological Society Press, St. Paul, MN, U.S.A.

Zhang, S., and Klessig, D. F. 2001. MAPK cascades in plant defense signaling. Trends Plant Sci. 6:520-527. 